\title{
ANALISIS FAKTOR YANG BERHUBUNGAN DENGAN WAKTU TANGGAP PADA PASIEN GAWAT DARURAT DI INSTALASI GAWAT DARURAT (IGD) RSUD A.WAHAB SJAHRANIE SAMARINDA
}

\author{
Wiyadi1), Gajali Rahman2) \\ 1,2Dosen Jurusan Keperawatan, Poltekkes Kaltim \\ Email:Wiyadi1968@gmail.com
}

\begin{abstract}
Emergency Department (ED) is the gateway for entry of patients experiencing emergency department. The services provided by the emergency room are services that require fast, precise and careful handling in determining the emergency priorities of patients to prevent disability and death. The purpose of this research is to analyze the factors related to the response time of emergency patients in ED Hospital A.W Syahranie by using observational or descriptive designs. The design of this study was cross-sectional with accidental sampling method with a sample size of 323 respondents. The results of the study were analyzed univariate, bivariate and multivariate to look for the dominant factor in emergency response time in the emergency room at A.W Syahranie Hospital Samarinda. Univariate analysis looking for percentage and bivariate analyzed with Chi Square test while multivariate with logistic regression. The results obtained $P$ value $>0.05$ for factors of payment methods, attendance of staff, staff placement patterns, availability of brankers, and shifts and the value of $P<0.05$ for factors of patient arrival time, patient priorities, nurse tenure and nurse education level. The conclusion from the multivariate test found that the most dominant factor related to response time was the length of service of the nurse.
\end{abstract}

Keywords: factors, response time

\section{Abstrak}

Instalasi Gawat Darurat (IGD) merupakan pintu gerbang masuknya pasien yang mengalami gawat darurat. Pelayanan yang diberikan oleh IGD merupakan pelayanan yang memerlukan penanganan cepat, tepat dan cermat dalam menentukan prioritas kegawatdaruratan pasien untuk mencegah kecacatan dan kemtian. Tujuan peneltian ini adalah menganalisa factor yang berhubungan dengan waktu tanggap pasien gawatdarurat di IGD RSUD A.W Syahranie dengan mengunakan rancangan observasional atau diskripif. Design penelitian ini adalah cross secsional dengan metode samplingnya accidental sampling dengan besar sampel 323 responden. Hasil penelitian dianalisa univariate, bivariate dan multivariate untuk mencari factor yang dominan terhadap waktu tanggap pasien gawat darurat di IGD RSUD A.W Syahranie Samarinda. Analisa univariate mencari prosentasi dan bivariate dianalisa dengan Chi Square sedangkan multivariate dengan Regresi logistic. Hasil penelitian didapatkan nilai $P>0,05$ untuk factor cara pembayaran, keberadaan petugas, pola penempatan staf, ketersediaan branker, dan shif jaga dan nilai $P<0.05$ untuk factor waktu ketibaan pasien, prioritas pasien, masa kerja perawat dan tingkat pendidikan perawat. Kesimpulan dari uji multivariat didapatkan factor yang paling dominan yang berhubungan dengan waktu tanggap adalah masa kerja perawat.

Kata kunci: faktor-faktor, waktu tanggap

\section{PENDAHULUAN}

Instalasi Gawat Darurat (IGD) merupakan pintu gerbang masuknya pasien yang mengalami gawat darurat. Pelayanan yang diberikan oleh IGD merupakan pelayanan yang memerlukan penanganan cepat, tepat dan cermat dalam menentukan prioritas kegawatdaruratan pasien untuk mencegah kecacatan dan kematian ${ }^{1}$. Wilde (2013) telah melakukan penelitian dan hasilnya 
bahwa waktu tanggap (respon time) sangat penting terutama pada pasien penyakit jantung . Keterlambatan pada waktu tanggap awal dapat memperparah kondisi pasien bahkan dapat menyebabkan kematian². Ada beberapa factor yang mempengaruhi watu tanggap diantaranya adalah kararakter pasien, penempatan staf, ketersediaan stretcher, dan petugas kesehatan, waktu ketibaan pasien, pendidikan perawat, masa kerja perawat, ${ }^{3}$. Rumah sakit Abdul Wahab Syahranie belum ada penelitian tentang waktu tanggap psien gawat darurat di IGD, untk itu penelit tertarik untuk melakauka penelitian yang berkaiatn dengan waktu tanggap.

\section{METODE PENELITIAN}

Penelitian ini menggunakan rancangan peneltian diskriptif dengan pendekatan cross sectional dimana variable dependen dan independent di ambil secara bersamaan. Populasi pada peneliian ini adalah pasien yang datang ke IGD rerata setiap bulan 1500. Besar sampel pada penelitian ini adalah 316 responden, dengan metode samping Accidental sampling. Cara pengambilan sampel setiap pasien yang datang ke triase dilakukan penghitungan waktu tanggap dengan menggunakan penghitungan waktu (Stopwatch).

Analisa data meliputi data univariat, bivariat dan multivariat. Analaisa univariet untuk mencari frekuensi atau proporsi berbagai karakteristik variable meliputi factor keberadaan petugas, penempatan staf, ketersediaan branker, ketibaan pasien, prioritas pasien, shiff jaga, masa kerja, Pendidikan perawat dan waktu tanggap. Analisa bivariat untuk mencari hubungan antara variable dependen dengan variable independent. Analisa data bivariat ini menggunakan ui Chi Square dengan uji alternative Fisher Exact dan
Kolmogorov Smirnove. Analisa multivariat untuk mencari factor yang paling dominan dari beberapa factor yang mempengaruhi waktu tanggap. Analisa multivariat menggunakan uji Regresi logistic. Pada tahap awal dengan Regresi Logistik sederhana untuk menentukan factor yang memenuhi syarat untuk uji Regresi ganda.

\section{HASIL PENELITIAN DAN PEMBAHASAN}

Rumah Sakit A. Wahab Syaranie adalah rumah sakit pusat rujukan Nasional di Kaltim dengan Klaster A. RSUD A.WS memeliki beberapa sarana salah satunya adalah Intalasi Gawat darurat (IGD). IGD terletak di bagian depan bangunan rumah sakit. Gedung IGD terdiri dari 3 lantai. Lantai dasar berfungsi sebagai IGD, Lt 2 sebagai kamar bedah gawat darurat dan Lt 3 sebegai ruang perawatan HCU. IGD memiliki tenaga perawat sebanyak 65 orang dengan pembagian shiff 15 orang pershif dan 2 orang perawat ditempatkan di Triase.

Penelitian ini dilakukan di Instlasi Gawat Darurat RSUD A.W. Sjahranie Samarinda. Penelitian dilaksanakan mulai tanggal 1 Oktober sampai 10 Oktober 2019. Besar sampel pada penelitian ini adalah 323 responden.

Tabel 1. Data karakteristik responden pasien gawat darurat di IGD RSUD A.W Syahranie Samarinda

\begin{tabular}{lll}
\hline Usia & Frekuansi & Prosentasi \\
\hline$<18$ thn & 39 & $12.1 \%$ \\
\multicolumn{1}{c}{ Jumlah 18 tahun } & 284 & $87.9 \%$ \\
Jenis kelamin & 323 & $100 \%$ \\
Laki-laki & Frekunsi & Prosentasi \\
Perempuan & 182 & $56.3 \%$ \\
Jumlah & 141 & $43.7 \%$ \\
Jenis pembayaran & 323 & $100 \%$ \\
BPJS & Frekunsi & Prosentasi \\
Mandiri & 288 & $89.2 \%$ \\
Swasta & 28 & $8.7 \%$ \\
Jumlah & 7 & $2.2 \%$ \\
\hline
\end{tabular}


Pada penelitian ini berdasarkan usia hampir seluruhnya (87.9 \%) berusia dewasa artinya pasien yang berusia anak-anak hanya $12.1 \%$. Sedangkan berdasarkan jenis kelamin sebagian besar $(56.3 \%)$ adalah pasien laki-laki. Untuk kepesertaan jaminan kesehatan nasional baru 89.2 \% dan masih ada pasien yang membayar biaya rumah sakit secara mandiri.

Tabel..2. Keberadaan petugas Triase saat pasien datang di IGD RSUD A. W Syhranie Samarinda

Keradaan petugas

Tidak ada 1

Ada 322

Jumlah 323

Frekuensi

322

323

Berdasarkan table diatas bahwa petugas Triase hampir selalu ada di tempat saat pasien datang di IGD.

Tabel 3 Pola penempatan staf di Triase IGD RSUD A.W Syahranie Samarinda

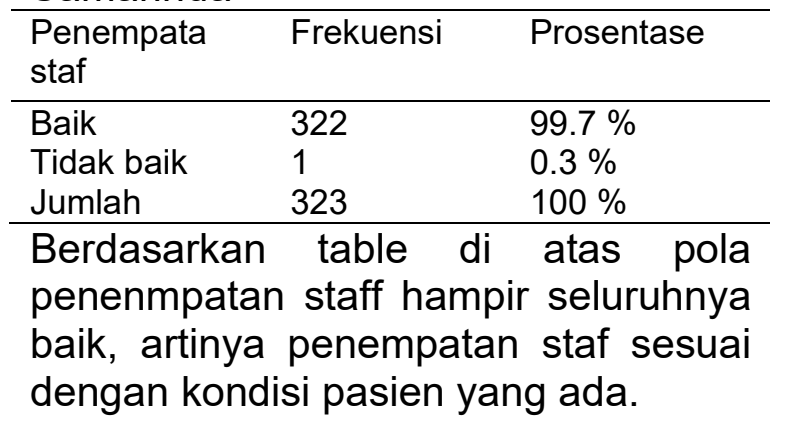

Tabel 4 Keberadaan Branker di IGD RSUD A.W Syahranie Samarinda

\begin{tabular}{lll}
\hline $\begin{array}{l}\text { Keberadaa } \\
\mathrm{n} \text { brankar }\end{array}$ & Frekuensi & Prosentase \\
\hline Ada & 323 & $100 \%$ \\
Tidak ada & 0 & 0 \\
Jumlah & 323 & $100 \%$ \\
\hline
\end{tabular}

Berdasarkan table diatas keberadaan Branker di Triase seslalu tersedia saat pasien datang di IGD RSUD A. W Syahranie Samarinda.

Tabel 5 Kondisi saat pasien datang di IGD RSUD A W Syahranie Samarinda. Kondisi Triase Frekuensi Prosent Prosentase

0Siblak $\quad 160 \quad 49.5 \%$

9\$iđak sibuk $\quad 163 \quad 50.5 \%$

10 animlah $\quad 323 \quad 100 \%$

Berdasarkan tebel diatas kondisi saat pasien sebagian besar $(50.5 \%)$ tidak sibuk,hal ini terjadi karena saat ini Rumah Sakit A.W Syahranie merupakan rumah sakit pusat rujukan untuk Provinsi Kalimantan Timur sehingga pasien yang datang di IGD benar-benar dalam kondisi kegawatan atau rujukan dari rumah sakit Kota Kabupaten yang ada di Kaltim.

Tabel 6 Prioritas pasien berdasarkan tingkat kegawatannya yang datang ke IGD RSUD A.W Syahranie Samarinda.

\begin{tabular}{lcc}
\hline Prioritas & -rekuensi & Prosentase \\
\hline I & 4 & $1.2 \%$ \\
II & 16 & $5.0 \%$ \\
III & 196 & $60.7 \%$ \\
IV & 104 & $32.2 \%$ \\
V & 3 & $9.0 \%$ \\
Jumlah & 323 & $100 \%$ \\
\hline
\end{tabular}


Berdasarkan tabel 6 sebagian besar $(60,7 \%)$ pasien yang datang ke IGD RSUD A. W Syahranie Samarinda adalah priritas III artinya pasien dalam kondisi mengancam nyawa dengan waktu tunggu maksimal 30 menit.

Tabel 7 Waktu tanggap pasien yang datang ke IGD RSUD A.W Syahranie Samarinda.

\begin{tabular}{ccc}
\hline Waktu tanggap & Frekuensi & Proentase \\
\hline$>5$ menit & 109 & $33.7 \%$ \\
$<5$ menit & 214 & $66.3 \%$ \\
Jumlah & 323 & $100 \%$ \\
\hline
\end{tabular}

Berdasarkan table di atas sebagian besar $(66.3 \%)$ waktu tanggap pasien yang datang ke IGD kurang dari 5 menit hal ini sesuai dengan standar IGD.

Tabel 8. Waktu pasien datang berdasarkan shif jaga perawat di IGD RSUD A.W Syahranie Samarnda.

\begin{tabular}{lll}
\hline Shif jaga & Frekuensi & Prosentase \\
\hline Pagi & 100 & $31.0 \%$ \\
Siang & 120 & $37.2 \%$ \\
Malam & 103 & $31.9 \%$ \\
Jumlah & 323 & $100 \%$ \\
\hline
\end{tabular}

Berdasarkan table diatas kedatangan pasien hampir sebagian (37.2 \%) pada shif siang, hal ini dikarenakan pada siang hari Poli Klinik sudah tutup dan Pelayanan di tingkat Primer atau pratama sudah tutup sehingga banyak pasien datang langsung ke IGD RSUD A.W Syahranie Samarinda.

Tabel 9. Hubungan factor jenis pembayaran dengan waktu tanggap pasien gawat darurat di IGD RSUD A.W Syahranie Samarinda

\begin{tabular}{llll}
\hline Jenis pembayaran & \multicolumn{2}{l}{ Waktu tanggap } & \\
\cline { 2 - 4 } & $<5$ menit & \rangle & 5 menit \\
\hline BPJS & 202 & 86 \\
Mandiri & 18 & 10 \\
Swasta & 5 & 2 \\
Jumlah & 225 & 98 \\
\hline
\end{tabular}

Berdasarkan hasil uji Chi Square terdapat 33,3 \% sel yang nilai expectacinya kurang dari 5 sehingga menggunakan uji alternative Kolmogorove Smirnove didapatkan hasil $p=1.000$ yang beratti lebih besar dari $\alpha=0.05$ artinya tidak ada hubungan yang signifikan.

Tabel 10. Hubungan Keberadaan perawat dengan waktu tanggap pasien gawat darurat di IGD RSUD A.W Syahranie Samarinda

\begin{tabular}{llll}
\hline Keberadaan & \multicolumn{3}{c}{ Waktu tanggap } \\
\cline { 2 - 4 } perawat & \multicolumn{1}{c}{$<5$ menit } & \multicolumn{1}{c}{5 me। } \\
\hline Tidak ada & 0 & 1 & \\
Ada & 225 & 97 & \\
Jumlah & 225 & 98 \\
\hline
\end{tabular}

Berdasarkan hasil uji Chi Square terdapat $50 \%$ sel yang nilai expectasinya kurang dari 5 sehingga digunkan uji alternative Fisher's Exact Test dengan hasil $p=0,303$ yang beratrti lebih besar dari $\alpha=0,05$ tidak ada hubungan yang signifikan.

Tabel 11. Hubungan factor penempatan staf dengan waktu tanggap pasien gawat di IGD RSUD A Wahab Syahranie Samarinda.

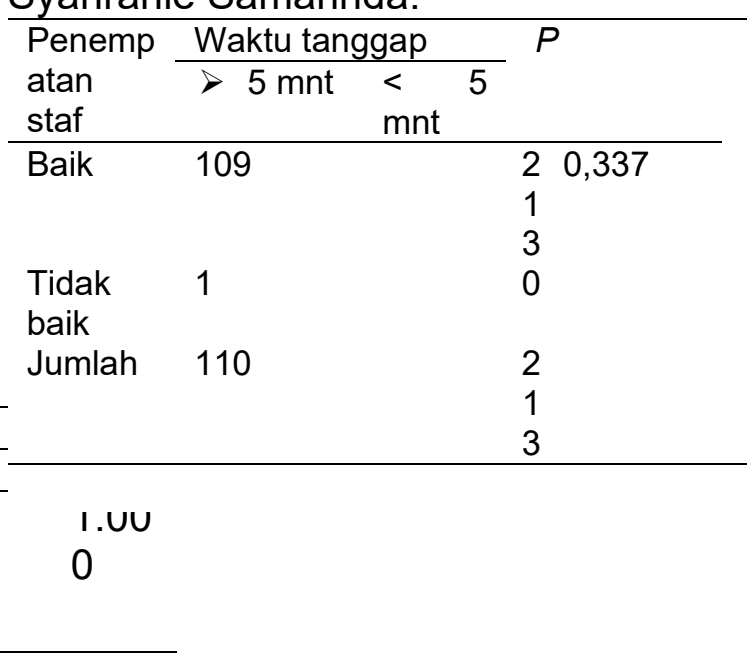


Dari hasil uji Chi Squere hubungan factor penempatan staf dengan waktu tanggap pasien di IGD RSUD A Wahab Syahranie didapatkan nilaiexpectasi kurang dari 5 ada 2 sel (50\%) artinya Uji Chi Squere tidak memenuhi persyaratan sehingga digunkan hasil uji alternative Fisher's exact Test dengan hasil $p=0,337$ yang berarti lebih besar dari $\alpha=0,05$, tidak ada hubungan yang signifikan.

Pada penelitian ini berdasarkan uji Chi Square tidak ada hubungan antara factor keberadaan petugas dengan waktu tanggap pasien gawatdarurat di IGD, hal dikarenakan keberadaan petugas ada setiap saat. Kondisi ini memang harus terjadi karena IGD yang merupakan pintu masuk dari sebuah rumah sakit dan RSUD A.W Syahranei sebagai rumah sakit rujukan ke tiga yang mewajibkan petugas selalu ada selama 24 jam sesuai standar pelayanan IGD untuk rumah sakit Type $A^{7}$. Hal ini sesuai dengan hasil penelitian Fadhilah (2015) tidak ada hubungan antara keberadaan perugas dengan waktu tanggap dimana petugas selalu ada saat pasien datang ${ }^{9}$. Hubungan antara penempatan staf dengan waktu tanggap pasien gawat darurat di IGD tidak signfikan, artinya bahwa penempatan staf sesuai dengan kondisi ruangan, bila jumlah pasien meningkat maka, jumlah tenaga yang ditempatkan di Triase dapat ditambah jumlahnya. Hal ini sama dengan hasil penelitian Fadhilah (2015) tidak ada hubungan yang signifikan $(P=1.000){ }^{9}$.

Pada penelitian ini hubungan keberadaan brankar dengan waktu tanggap didapatkan tidak signifikan $(p=1.000)$, di IGD RSUD A.W Syahrenie jumlah brankar yang tersedia di ruang Triase sangat memenuhi jumlahny sehingga setiap kedatangan pasien brankar selalu ada. Hal sesuai denga standar pelayanan IGD ${ }^{7}$. Penelitian ini sesuai dengan hasil penelitian Fadhilah bahwa keberadaan Brankar tidak ada hubungan dengan waktu tanggap pasien gawat darurat yang datang ke IGD ${ }^{9}$. Hubungan Waktu ketibaan dengan waktu tanggap pasien gawatdarurat di IGD memiliki hubungan yang signifikan $(P=0.022)$ artinya kondisi sibuk dapat menyebabkan waktu tanggapnya lebih panjang dari pada saat tidak sibuk. Hubungan factor prioritas pasien dengan waktu tanggap pasien gawatdarurat di IGD memiliki hubungan nyang signifikan $(P=0.000)$, artinya pasien yang memiliki prioritas I akan lebih cepat mendapatkan waktu tanggap dan pasien yang prioritasnya II - V akan mendapatkan waktu tanggapnya yang lebih lama. Hal ini sama dengan hasil penelitian Apriani (2017) dan Mahyati (2015) bahwa pasien yang prioritas I cepat mendapat waktu tanggap ${ }^{6}$. Hal ini juga sesuai dengan hasil penelitian Santoso (2016) bahwa kondisi pasien yang gawat darurat mempengaruhi waktu tanggap dimana pasien yang gawat daurat memiliki peluang 5 kali lebih besar untuk waktu tanggap seseui standar ${ }^{10}$ Hubungan factor shif jaga dengan waktu tanggap tidak terdapat hubungan yang signifikan $(p=0.093)$ hal ini dikarena pada penelitian ini jumlah kunjungan pada shif pagi, siang dan malam hampir merata. Pada penelitian ini berbeda dengan hasl penelitian Mahyawati (2015) bahwa perbedaan shif jaga dapat mempengaruhi kecepatan tanggap karena adanya sirkadian ritme dimana pada siang dan malam hari kondisi tubuh mulai menurun 1 .

Pada penelitian ini factor masa kerja berhubungan secara signifikan $(P=0.000)$ dengan waktu tanggap. Semakin lama bekerja maka tingkat ketrampilan samakin meningkat atau mahir. Hal ini sesuai dengan hasil penelitian Ahmad (2012) bahwaa 
masa kerja perawat yang bekerja di IGD Berhubungan dengan waktu tanggap pasien gawatdarurat. Hubungan factor Pendidikan berdasarkan jumlah pasien dengan waktu tanggap psein gawatdarurat di IGD memiliki hubungan yangbsignifikan $(P=0.000)$, hal ini sesui dengan teori bahwa Pendidikan akan mempengaruhi kemampuan tindakan atau ketrampilan. Menurut Tuwo (2019) semakin tingkat Pendidikan maka akan meningkatkan ketrampilan dalam menilai pasien ${ }^{11}$, hal ini juga sesui dengan penelitian Apriani (2017) bahwa tingkat pendidikan dapat meingkatkan kecepatan menilai tingkat kegawatdaruratn pasien. ${ }^{6}$.

Berasarkan hasil pemodelan multivariate II didapatkan factor yang dominan berhubungan dengan waktu tanggap pada penelitian adalah lama kerja perawat di IGD RSUD A. W.Syahranie dengan nilai $P=0.00$ dengan Odds Ratio 7,531 yang artinya pada orang yang memiliki masa kerja lebih dari 5 tahun akan melakukan waktu tanggapnya lebih cepat sebanyak 7,5 kali dibandingkan dengan perawat yang memiliki masa kerja kurang dari 5 tahun. Hal ini berbeda dengan hasil penelitian Maatilu yang menyatakan tidak ada perbedaan antara lama kerja perawat dengan waktu tanggap terhadap pasien gawat darurat di IGD RSUP. Prof. Dr . R. D. Kandou Manado ${ }^{12}$.

\section{SIMPULAN}

Berdasarkan penelitian ini dapat disimpulkan dari beberapa factor yang berhuugan dengan waktu tangap adalah factor waktu ketibaan, prioritas pasien, Pendidikan perawat, dan masa kerja perawat sementara factor yang tidak berhubungan adalah jenis pembayaran, keberadaan petugas, penempatan petugas, keberadaan branker dan shiht jaga perawat. Pada penelitian ini factor yang paling dominan berhubungan dengan waktu tanggap adalah masa kerja perawat.

\section{Ucapan terima kasih}

Ucapan terima kasih kami sampaikan kepada Direktur Poltekkes Kemenkes Kalimantan Timur yang telah memberikan kesempatan kepada kami tim peneliti untuk melakukan penelitian dengan diberikan support dana. Ucapan terima kasih juga kami sampaikan kepada Ka.Pusat Penelitian dan Pengabdian masyarakat yangtelah memili judul penelitian ini untuk mendapat dana DIPA Poltekkes Kemenkes Kalimanta Timur.

\section{DAFTAR PUSTAKA}

1. Mahyawati, widaryati. Hubungan Kegawadaruratan Pasien dengan Waktu Tanggap Perawat di IGD RS PKU Muhammadiyah Yogyakarta. e-Jurnal keperawatan (e-kp). 2015:14.

2. Rose L, Scales DC, Atzema C, et al. Emergency department length of stay for critical care admissions a population-based study. Ann Am Thorac Soc. 2016;13(8):1324-1332. doi:10.1513/AnnalsATS.201511$7730 \mathrm{C}$

3. WILDE ET. DO EMERGENCY MEDICAL SYSTEM RESPONSE TIMES MATTER FOR HEALTH OUTCOMES. Health Econ. 2013;22:790-806. doi:10.1002/hec.2851

4. Diskominfo Kaltim. Profil Kalimantan Timur. 2018.

5. BPJS Kesehatan. Sistem Rujukan BPJS Kesehatan Berjenjang Terbaru Agustus 2018. 2018:1-16. bpjskesehatan.go.id/bpjs/dmdocume nts/7c6f09ad0f0c398a171ac4a6 678a8f06.pdf.

6. Apriani SF. Hubungan 
kegawatdaruratan dengan waktu tanggap pada pasien jantung koroner. J Kesehat. 2017;8(3):471-477.

7. Kemenkes RI. Standar Instalasi Gawat Darurat (IGD) Rumah Sakit. 2009. 2009:29.

8. Kemnenkum dan Ham. Undang Undang No 36 Tahn 2014 Tentang Tenaga Kesehatan.; 2014.

9. Fadhilah N, Harahap WA, Lestari Y. Faktor-faktor yang Berhubungan dengan Waktu Tanggap pada Pelayanan Kasus Kecelakaan Lalu Lintas di Instalasi Gawat Darurat Rumah Sakit Umum Pusat Dr. M . Djamil. J Kesehat Andalas. 2015;4(1):195-201.
10. Santoso IM. Faktor-Faktor Yang Mempengaruhi Waktu Tanggap Pasien Di Instalasi Gawat Darurat Rumah Sakit X. 2016;2(8):467-472.

11. Tuwo PG, Rumampuk JF, Katuuk ME. Hubungan Ketepatan Triase Dengan Response Time Rumah Sakit Tipe C. 2019;7.

12. Maatilu V, Mulyadi, Malara RT. Faktor-Faktor Yang Berhubungan Dengan Response Time Perawat Pada Penanganan Pasien Gawat Darurat Di Igd Rsup Prof. Dr . R. D. Kandou Manado. $J$ Keperawatan UNSRAT. 2014;2(2). 